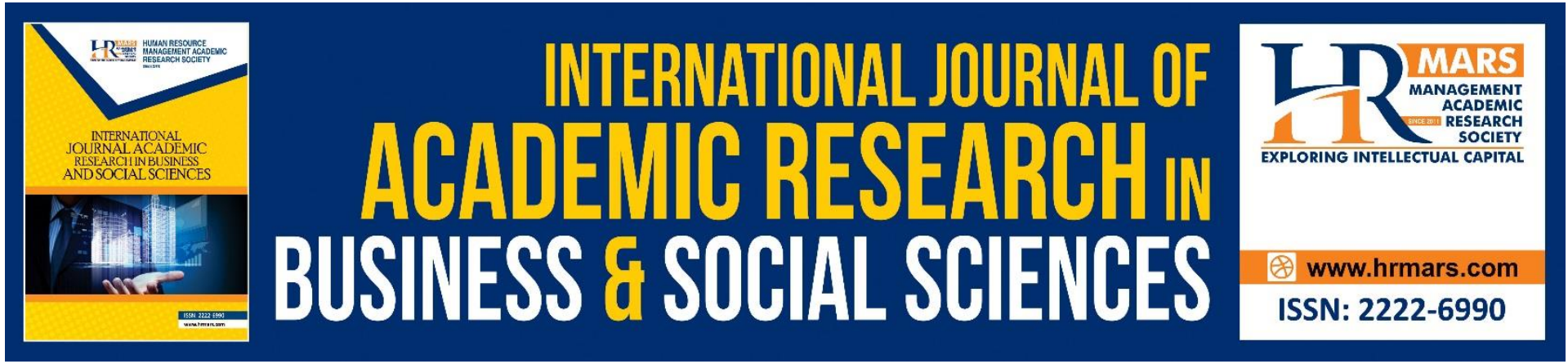

\title{
Minimizing the Total Cost of Inventory by Using Artificial Bee Colony Algorithm
}

Nurul Syakira Mohd Zin, Siti Hafawati Jamaluddin, Norwaziah Mahmud, Nur Syuhada Muhammat Pazil

To Link this Article: http://dx.doi.org/10.6007/IJARBSS/v11-i7/10334

DOI:10.6007/IJARBSS/v11-i7/10334

Received: 16 May 2021, Revised: 18 June 2021, Accepted: 05 July 2021

Published Online: 27 July 2021

In-Text Citation: (Zin et al., 2021)

To Cite this Article: Zin, N. S. M., Jamaluddin, S. H., Mahmud, N., \& Pazil, N. S. M. (2021). Minimizing the Total Cost of Inventory by Using Artificial Bee Colony Algorithm. International Journal of Academic Research in Business and Social Sciences, 11(7), 1147-1154.

Copyright: @ 2021 The Author(s)

Published by Human Resource Management Academic Research Society (www.hrmars.com)

This article is published under the Creative Commons Attribution (CC BY 4.0) license. Anyone may reproduce, distribute, translate and create derivative works of this article (for both commercial and non-commercial purposes), subject to full attribution to the original publication and authors. The full terms of this license may be seen at: http://creativecommons.org/licences/by/4.0/legalcode

Vol. 11, No. 7, 2021, Pg. 1147 - 1154

Full Terms \& Conditions of access and use can be found at http://hrmars.com/index.php/pages/detail/publication-ethics 


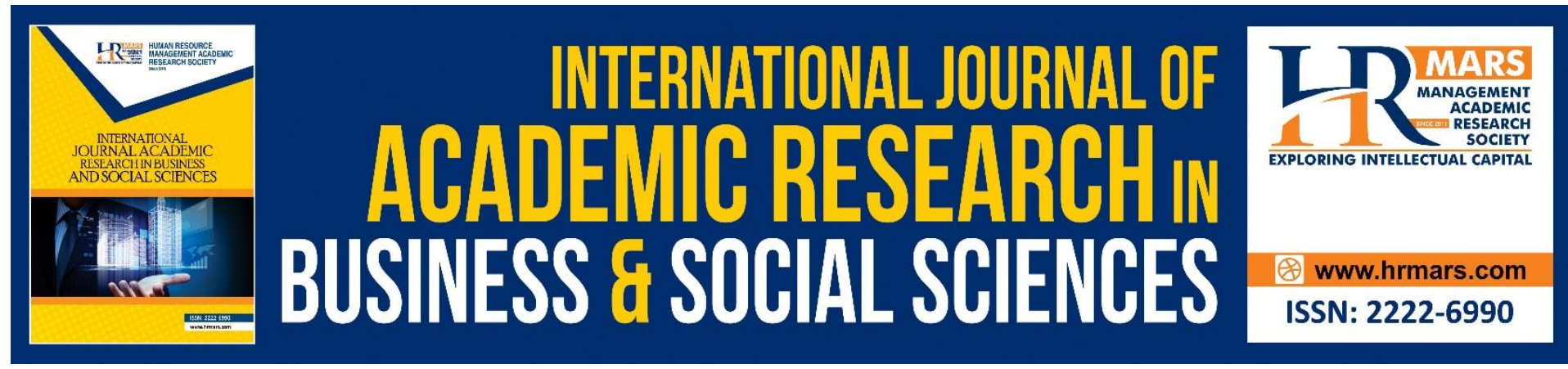

\title{
Minimizing the Total Cost of Inventory by Using Artificial Bee Colony Algorithm
}

\author{
Nurul Syakira Mohd Zin ${ }^{1}$, Siti Hafawati Jamaluddin¹, Norwaziah \\ Mahmud $^{1}$, Nur Syuhada Muhammat Pazil ${ }^{2}$ \\ ${ }^{1}$ Universiti Teknologi MARA Cawangan Perlis, Kampus Arau, 02600 Arau, Perlis, Malaysia, \\ Universiti Teknologi MARA Cawangan Melaka, Kampus Jasin, 77300 Merlimau, Melaka, \\ Malaysia \\ Email: hafawati832@uitm.edu.my
}

\begin{abstract}
Inventory denotes the assets and important resources utilised in an organisation or industry in which it offers various benefits for firm cash flow and persistent viability. If the production inventory of a company faces shortage or other problems such as greater operating cost due to interest payments on loan cash, the management will be in a critical situation, thereby leading to loss of customers and profits. This encourages organisations to implement inventory control, which aims for the lowest total cost of inventory, among others. Therefore, this study employed the Artificial Bee Colony $(A B C)$ algorithm to ascertain the minimum total cost of inventory. The algorithm characterised a swarm-based meta-heuristic algorithm comprised of three divisions of bee troops in the $A B C$ model, namely employed, onlooker, and scout bees. The resulting outcomes revealed a minimum total cost of inventory obtainable of RM45.38, with an optimal order quantity of 37 units.
\end{abstract}

Keywords: Inventory, Inventory Control, Artificial Bee Colony $(A B C)$ Algorithm, Minimum Total Cost, Optimal Order Quantity

\section{Introduction}

According to Samak-kulkarni and Rajhans (2013), resources meant for use in an organisation or industry are called inventory. In the process, the manager is tasked with deciding the amount of safety stock can be kept in the production system as it is their responsibility to ensure the service level or minimise the inventory cost. Therefore, an accurate model for the inventory is needed to successfully attain the desired goal. Furthermore, Chuka, Oguejiofor, and Sunday (2016) have described business, organisation, or company holding the goods and materials otherwise known as inventory for the purpose of manufacturing, support activities, and trade. Moreover, Lemke and Lemke (2015) have detailed inventory as a weighty asset in most manufacturing companies, which is useful for generating a positive effect on their cash flow and continued viability. Therefore, inventory is undoubtedly essential for any entities to consistently grow and survive in the industry, whereby issues like shortage or greater operating cost due to interest payments on loan cash will be disastrous. 
A company needs to fulfil customer demands by having enough inventory in the warehouses; however, these inventories come with holding costs and may be frozen funds that can be lost (Sohail and Sheikh, 2018). A stock system is an arrangement of plans controlling and preserving the inventory levels, which will allow the company to be notified of when to replenish theirs stocks and the size of orders for proceed (Samak-kulkarni \& Rajhans, 2013). In real-life cases, the stock demands are uncertain and difficult to forecast due to seasonal changes. Thus, ordering the stocks at an accurate period and amount is essential to minimise the overall cost and increase the company profits.

Other than that, they may face difficulties in determining the order size, whereby large stock sizes ordered allows the purchasing cost to be reduced. However, if the ordered stocks come along with a holding cost, it can be higher if they are kept for a long time since they are more than the demand. This situation will increase the holding cost and become a loss if the stocks are damaged or spoiled. In contrast, stocks ordered in small size despite higher demand also cause loss to the company. Another common issue is ordering the stocks at the right time, whereby the constant availability in the warehouse may render them unsure of the minimum stock required for restock. In sum, Barwa (2015) has said that the organisation or industry would require the stock directly when the stock is at the least available.

Singh and Kumar (2015) have proposed the use of Genetic Algorithm (GA) in solving the inventory problem, whereby they aimed to determine the goods for emphasis and the number of inventory levels for storage by a specific supply chain member. Through this algorithm, the supply chain cost can be reduced when controlling the level of stocks at the respective supply chain members in the upcoming period. However, a high risk has to be dealt with supply chains where a deficiency of stocks can interrupt then general manufacturing strategy or inventory supervision, whereas a surplus on the inventory level is a managerial obstacle (Tanthatemee \& Phruksaphanrat, 2017). Therefore, Tanthatemee and Phruksaphanrat (2017) have proposed the Fuzzy Logic Control (FLC) and Fuzzy Inventory Control (FIC) to calculate the reorder points based on the demand capacities was handled by the FIC model with the help of the fuzzy logic toolbox of MATLAB. Moreover, the Economic Order Quantity (EOQ) stochastic model was matched to check the FIC system functions.

The Optimal Order Quantity (EOQ) and total cost formula can be obtained through Eq. (1) and Eq. (2);

$\mathrm{EOQ}=\mathrm{O}=\sqrt{\frac{2 \mathrm{PC}_{0}}{C_{h}}}$

Total Cost $=P C+\frac{P}{O} C_{0}+\frac{O}{2} C_{h}$

where;

$P C=$ Price cost

$\frac{P}{O} C_{0}=$ Yearly ordering cost

$\frac{O}{2} C_{h}=$ Yearly holding cost 
In this study, data from the website of Lokad Quantitative Supply Chain Company is adopted which includes the following variables: yearly demand of inventory items $(P)$, carrying cost of one unit per year $\left(C_{h}\right)$, and ordering cost per order in order $\left(C_{0}\right)$ to minimise the total cost of inventory. This data is a software company with a strong technological and mathematical centre, with aims of introducing state-of-the-art technology and science to supply chains.

The Artificial Bee Colony $(A B C)$ algorithm is used to obtain the minimum total cost since it is one of the algorithms highly effective in inventory control optimisation.

\section{Methodology}

Xu, Fan, and Yuan (2013) have attributed optimisation problems in several applicable areas, such as engineering, economy, and management. Thus, the social behaviour of fish, insect, or bird has inspired scholars towards resolving such complications, namely by introducing the swarm intelligence algorithm. Examples of such algorithms over the past years include Artificial Bee Colony ( $A B C$ ), Firefly Algorithm (FA), Ant Colony Optimisation (ACO), and Particle Swarm Optimisation (PSO). Among these, Xu et al. (2013) have underlined ABC to perform fundamentally better, or, if nothing else, practically comparable to other swarm intelligence algorithms due to the experiments carried out via vast benchmark arrangement.

In 2005, Dervis Karaboga introduced the $A B C$ algorithm as a swarm-based meta-heuristic algorithm, announcing its function for optimising numerical difficulties and the intelligent foraging behaviour of honey bee swarm as an inspiration. According to Hadidi, Azad, and Azad (2019), the colony in the $A B C$ model contains three divisions of bee troops, which are employed, onlooker, and scout bees. In practice, the colony is divided into two: employed artificial bees and onlooker bees. Employed bees will become scout bees once they abandon a source of food, whereby each food source is assigned to one employed bee. The illustration of this stages can be described as in Figure 1 below. 


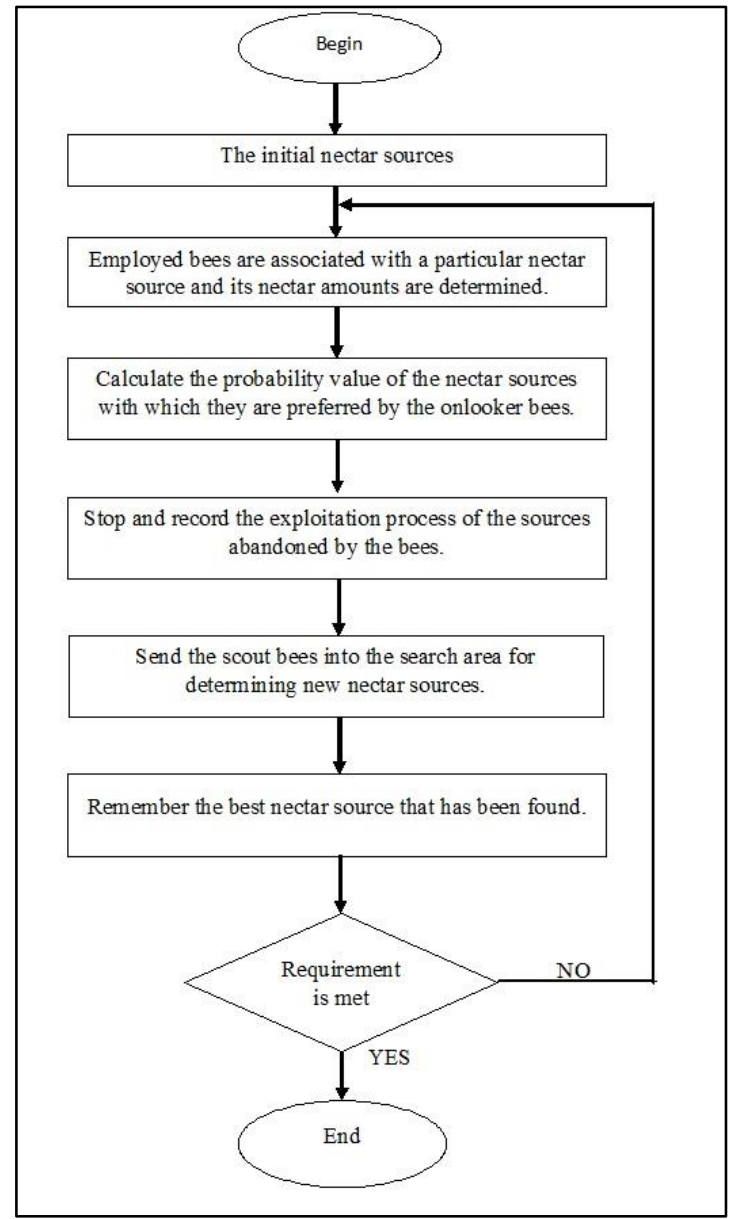

Figure 1: Flowchart of $A B C$ Algorithm

(Source: Guo, Li, Tang \& Li, 2017)

Based on the above figure, this algorithm can be categorised as four stages, which are Initialisation, Employed Bees, Onlooker Bees, and Scout Bees.

Phase 1: Initialisation of the parameters and population

In initialisation phase, the scout bees will fix the control parameter and adjust the vectors of the population of food sources $\left(x_{q}\right)$ entirely. However, every food source $\left(x_{q}\right)$ is a key vector to the problem of optimisation and $n$ variables, $x_{q} m ; m=1 \ldots n$ is embraced by every vector, which is to be boosted for minimising the objective function.

Calculation of the initialisation goal is given in Eq. (3) below:

$$
x_{q m}=c_{m}+\operatorname{rand}(0,1)\left(d_{m}-c_{m}\right)
$$

where rand $(0,1)$ is a random number inside $[0,1]$ based on the normal distribution, and $c_{m}$, $d_{m}$ are the lower and higher bounds of the parameter $x_{q m}$, respectively.

Phase 2: Employed bee phase

In this phase, employed bees hunt for new food sources $\left(d_{q}\right)$, which contain additional nectar within the area of the food source $\left(x_{q}\right)$, depending on the knowledge and nectar value in their memory. They would recognise a neighbour's food source and then calculate its 
profitability (fitness). If the nectar value of the new food source is lower than the old one, they will abandon latter.

Calculation for getting the neighbour food source is defined in Eq. (4) below:

$d_{q m}=x_{q m}+\varphi_{q m}\left(x_{q m}-x_{l m}\right)$

where $x_{i}$ is a casually preferred food source $(m)$ is an arbitrarily selected parameter index, and $\varphi_{q m}$ is an arbitrary figure inside the range $[-1,1]$.

Once they have successfully made the new food source $\left(d_{q}\right)$, an acquisitive choice is applied between $d_{q}$ and $x_{q}$. Later, the fitness value of the solution ( fitval $\left(x_{q}\right)$ ) may be computed for the minimisation problem by working on the following formula:

$$
\text { fitval }_{q}\left(x_{q}\right)=\left\{\begin{array}{lll}
\frac{1}{\left(1+f_{q}\left(x_{q}\right)\right)} & \text { if } & f_{q}\left(x_{q}\right) \geq 0 \\
1+a b s\left(f_{q}\left(x_{q}\right)\right) & \text { if } & f_{q}\left(x_{q}\right)<0
\end{array}\right.
$$

Where $f_{q}\left(x_{q}\right)$ is the objective function value of the solution $x_{q}$.

\section{Phase 3: Onlooker bee phase}

The employed bees offer the probability values as computed using the fitness, which will be utilised by the onlooker bees in the $A B C$ algorithm to select a food source. To achieve the goal, a fitness based selection method can be utilised.

The probability value $\left(T_{q}\right)$ in which $x_{q}$ is selected by an onlooker bee can be computed by using the Eq. (6) below:

$$
T_{q}=\frac{\operatorname{fitval}_{q}\left(x_{q}\right)}{\sum_{q=1}^{S N} \text { fitval }_{q}\left(x_{q}\right)}
$$

where fitval $_{q}\left(x_{q}\right)$ is the fitness value of the $q^{\text {th }}$ solution. Eq. (4) can be used to choose a neighbourhood source $\left(d_{q}\right)$ after the onlooker bees have selected the food source $\left(x_{q}\right)$ and the fitness value is calculated by using the Eq. (6). Meanwhile, in terms of the employed bee, the onlooker bee generates a modification in the position of her memory and tests the candidate source fitness. If the fitness is lower than the former one, the bee remembers the new position and ignores the former.

\section{Phase 4: Scout bee phase}

Unemployed bees that collect their own food sources are called scouts. Similarly, employed bees whose solution cannot be enhanced over an encoded number of trials as specified by the $A B C$ algorithm consumer, otherwise known as the "limit" or "abandonment criteria", would be the scouts and their solutions are neglected. Then, the differing solutions will be noticed by the altered scouts. For instance, if the solution $x_{q}$ has been neglected, the new solution found by the scout previously the employed bees of $x_{q}$ can be defined. Hence, 
originally unfortunate sources or made unfortunate due to misuse are uninhibited, whereby an unconstructive feedback behaviour will occur to equalise the encouraging feedback.

\section{Result and Discussion}

Table 1 shows that the maximum number of iterations is 200 , population size is 100 , and the number of onlooker bees that is equal to the number of populations (i.e. 100). Meanwhile, the abandonment limit parameter was approximately the multiples of 0.6 with the number of variables and the population size and acceleration coefficient equal to 1 , respectively.

Table 1: Parameter Settings for ABC Algorithm

\begin{tabular}{|l|c|c|}
\hline \multicolumn{1}{|c|}{ Description } & Symbol & Value \\
\hline Maximum Number of Iteration & Maxlt & 200 \\
\hline Population Size (Colony Size) & nPop & 100 \\
\hline Number of Onlooker Bees & nOnlooker & 100 \\
\hline Abandonment Limit Parameter (Trial Limit) & L & 120 \\
\hline Acceleration Coefficient Upper Bound & a & 1 \\
\hline
\end{tabular}

Through the parameters used in Table 1, the minimum total cost of inventory was RM45.38, whereas the ordering cost per order was RM711.22. Then, the optimal order for the item of the inventory (i.e. connector) was 37 units. Thus, it could be concluded that the optimal solution for the minimising total cost of inventory by using the $A B C$ algorithm was RM45.38 at 37 units of optimal order quantity.

\section{Conclusion}

The inventory in a warehouse has to be enough to fulfil customer demands while the manager has to decide the amount of safety stock can be kept in the production system as they are responsible for the service level or for minimising the inventory cost. In case of lacking inventories in the business for manufacturing or issues such as increased operational expenses triggered by interest rates on loan cash, the company will be in a critical state and result in loss of clients and sales. This situation has led to companies or industries applying many strategies to control the inventory.

To find the minimum total cost of inventory by using $A B C$ algorithm, a set of data was adopted from the website of Paris-based Lokad Quantitative Supply Chain Company. The variables implemented were the yearly demand of inventory items, carrying cost of one unit per year, and ordering cost per order. This study specifically utilised data for the used item, namely the connector, which was of the electrical equipment category. Then, the MATLAB software version R2018a was employed as a tool to minimise the cost of inventory items by using the $A B C$ algorithm. The result showed the best solution for the minimum total cost of inventory possibly obtained at RM45.38, with 37 units of optimal order quantity. 
To encourage future researchers towards generating better outcomes in minimising the total cost, it is recommended for them to increase the number of populations or the number of iterations (i.e. instead of 100 populations and 200 iterations in the $A B C$ algorithm). The higher the number of population and iteration, the bigger the random number generated and the more accurate the best solution would be. Besides, future researcher can utilise any other methods or improvements on the $A B C$ algorithm to minimise the total cost of inventory, such as the Improved Artificial Bee Colony (IABC) algorithm. This is attributable to bees in IABC algorithm that explore more in searching for the best food source compared to the original $A B C$ algorithm.

\section{References}

Barwa, T. M. (2015). Inventory Control as an Effective Decision-Making Model and Implementations for Company 's Growth. 3(5), 465-472.

Chuka, C. E., Oguejiofor, N. J., \& Sunday, A. C. (2016). Evaluation and Optimization of Inventory Control Systems in Small and Medium Scale Industries. 2(1), 1-13.

Hadidi, A., Azad, S. K., \& Azad, S. K. (2019). Structural Optimization Using Artificial Bee Colony Algorithm Structural optimization using artificial bee colony algorithm. May 2014.

Guo, Y., Li, X., Tang, Y., \& Li, J. (2017). Heuristic Artificial Bee Colony Algorithm for Uncovering Community in Complex Networks. 2017.

Lemke, S. W., \& Lemke, S. (2015). Inventory Optimization in Manufacturing Organizations.

Samak-kulkarni, M. S. M., \& Rajhans, N. R. (2013). Determination of Optimum Inventory Model for Minimizing Total Inventory Cost. 51(NUiCONE 2012).

Singh, S. R., \& Kumar, T. (2015). Inventory Optimization in Efficient Supply Chain Management. March.

Sohail, N., \& Sheikh, T. H. (2018). A study of inventory management system case study. Journal of Adv Research in Dynamical \& Control System, 10(10), 1176-1190.Tanthatemee, T., \& Phruksaphanrat, B. (2017). Fuzzy Inventory Control System for Uncertain Demand and Supply. March 2012.

Xu, Y., Fan, P., \& Yuan, L. (2013). A Simple and Efficient Artificial Bee Colony Algorithm. 